\title{
Tropical Diabetic Hand Syndrome in Patients with Diabetic Nephropathy
}

\author{
Hermina Novida, Budi Dharma, Agung Pranoto, Soebagijo Adi, Sri Murtiwi and Sony Wibisono \\ Metabolic Division of Endocrinology, Department of Internal Medicine, Faculty of Medicine, Universitas Airlangga/ Dr. \\ Soetomo General Hospital Campus A, Jl. Prof Moestopo 47 Surabaya 60132 Indonesia
}

apji@fk.unair.ac.id

Keywords: Complications of Diabetes Mellitus, Diabetes Mellitus type 2, Diabetic Nephropathy Syndrome, Terminal Stage, Tropical Diabetic Hand.

\begin{abstract}
Diabetic nephropathy syndrome is a condition of dysfunction in the vascular endothelial, smooth muscle cells of the blood vessels, as well as in the renal mesangial cells. This causes the occurrence of microvascular locus ischemic and local hypoxia 2. Diabetic nephropathy slows the wound healing process of Tropical Diabetic Hand Syndrome (TDHS) which is a specific complication in the hands experienced by patients with diabetes mellitus (DM). A patient presented with type 2 DM who had complications of TDHS and diabetic nephropathy. The risk factors for TDHS in these patients are female gender, age 52 years, poor glycemic control, and delay in seeking treatment. The terminal nephropathy condition of terminal diabetes has a poor prognosis in TDHS and the sepsis complication of TDHS is a risk factor for worsening renal function in diabetic nephropathy. TDHS management includes hospitalization, elevation of the affected hand, optimal blood glucose control, antibiotics and wound care in the form of incision, debridement, and drainage, if necessary, for further surgery and other rehabilitation measures. The approach of diabetic nephropathy therapy includes diagnosis, detecting other comorbid conditions, blood glucose regulation, hypertension regulation and proteinuria, dietary regulation, and multifactorial intervention. Education for TDHS patients and diabetic nephropathy is still the most important prevention tool in developing countries.
\end{abstract}

\section{INTRODUCTION}

Tropical Diabetic Hand Syndrome (TDHS) is a specific complication of the hands experienced by people with diabetes mellitus (DM) in tropical countries. This syndrome includes localized cellulitis, which can be progressive and fulminant, developing into hand sepsis and gangrene. Several case reports indicate serious complications from TDHS, namely permanent disability and death (Akhuemokhan et al., 2011).

Diabetic nephropathy is the leading cause of kidney disease in patients with renal replacement therapy and occurs in $44 \%$ of all DM patients, type 1 and type 2. In diabetic nephropathy dysfunction occurs in vascular endothelial cells, smooth muscle cells of the blood vessels, and in renal mesangial cells. This condition causes microvascular abnormalities of locally ischemic locus and hypoxia 2 (Afshinnia and Brosius, 2015). Diabetic nephropathy can slow the wound healing process of TDHS and vice versa for sepsis complications in and
TDHS is a risk factor for worsening renal function in diabetic nephropathy. Management of DM patients with TDHS and diabetic nephropathy requires a comprehensive management strategy in order to reduce mortality and morbidity rates both from complications of infectious conditions and the progression of renal function.

In this case report, we will report a diabetes mellitus patient who has complications of TDHS and diabetic Nephropathy.

\section{CASE}

A female patient, Mrs. E, 52 years old, a chef, was hospitalized in the Intermediate Treatment Room of Dr. Soetomo General Hospital on February 27, 2016. The patient had major complaints of shortness of breath for 5 days before hospitalization and 2 days before hospitalization. Shortness of breath did not increase during activity and decrease at rest. It was not accompanied by complaints of a cough and 
fever, but swollen legs were experienced by the patient for the 5 days before hospitalization accompanied by decreased urine production $\pm 1-1.5$ glasses every day, nausea and vomiting were experienced for 3 days before hospitalization, and 23 times per day vomiting frequency. Her body was weak, she experienced lethargy, was pale and had a decreased appetite for 7 days before hospitalization.

A festering wound on the upper right arm appeared 20 days before hospitalization, starting from a blister injury from falling when shopping in the market. The wound grew larger and began to ooze pus followed by redness, swelling, and pain. The patient treated her wound with alcohol and antiseptic solution. The patient complained of fever for 2 weeks before hospitalization, which could be brought down with the administration of febrifuge but a few moments later the fever returned. The patient was taken by the family to seek treatment for 5 days in a private hospital before hospitalization. The patient was treated with wound care, but the patient's condition worsened and was referred to Dr. Soetomo hospital.

Her previous disease history was that she had had DM since 2006, usually taking glibenclamide, but not regularly. There was no history of high blood pressure, previous dialysis and surgery reported. There was no history of drinking herbs, and no history of taking pain medication. Her family history was that her mother suffered from diabetes; however, there was no history of high blood pressure in the family reported by the patient.

Physical examination: the patient had a generally weak condition, with compos mentis consciousness. Blood pressure was $140 / 80 \mathrm{mmHg}$, pulse $106 \mathrm{x} /$ minute and breath frequency $30 \mathrm{x} /$ minute, with body temperature of $36.8 \mathrm{C}$. On examination her head and neck were conjunctival anemic, the sclera was not jaundiced, and there was no cyanosis. The patient's jugular venous pressure also was not increased and no lymph node enlargement was detected. On chest examination, there was symmetrical chest motion, no retraction, single S1S2 heart sound without any additional sound. Vesicular respiratory voices in both lung fields had no roughness or wheezing. On abdominal examination, it was found flat, supple, no tenderness, and normal bowel sounds. There was no enlargement of the liver or lien. On examination of the limbs there were warm acral areas, with edema in both legs. Sensory and motoric examination of the extremities found them to be within normal limits with an anklebrachial index (ABI) value 1.0. On examination of the right-sided local status, an injury to the central region of the brachial dextra with pus was found and at the bottom of the wound there was full slough $(+)$, with the size $9 \times 3 \mathrm{~cm}$ and $2 \mathrm{~cm}$ depth into the muscle, accompanied by signs of inflammation in the form of heat, dolor, rubor, tumor, and function laeasa.

Laboratory examination results: hemoglobin 8.8 $\mathrm{g} \%$, leukocytes $37,210 / \mathrm{mm}^{3}$, platelets $670.000 / \mathrm{mm}^{3}$, random blood glucose $197 \mathrm{mg} / \mathrm{dl}$, serum glutamic oxaloacetic transaminase (AST) $20 \mathrm{U} / \mathrm{L}$, serum glutamic pyruvic transaminase (ALT) $9 \mathrm{U} / \mathrm{L}$, total bilirubin 0.45 , direct bilirubin 0.16 , blood urea nitrogen (BUN) $114 \mathrm{mg} / \mathrm{dl}$, serum creatinine 10.67 $\mathrm{mg} / \mathrm{dl}$, estimated glomerular filtration rate (eGFR) $7.44 \mathrm{ml} / \mathrm{min} / 1.73 \mathrm{~m}^{2}$, potassium $6.47 \mathrm{meq} / \mathrm{L}$, sodium $126 \mathrm{meq} / \mathrm{L}$, chloride $90.2 \mathrm{meq} / \mathrm{L}$, albumin 2.6 , nonreactive HBsAg, partial thromboplastin time (PPT) 11.9 seconds (12.1 seconds control), activated partial thromboplastin time (aPTT) 35.0 seconds (control 22.8 seconds), Blood Gas Analysis pH 7.11, pCO2 $22 \mathrm{mmHg}$, pO2 $203 \mathrm{mmHg}, \mathrm{HCO} 37.0 \mathrm{mmol} / \mathrm{L}$, Beecf - $22.5 \mathrm{mmol} / \mathrm{L}, \mathrm{SO} 299 \%$.

Photo chest: Cor: cardiomegaly CTR 58\%, pulmo: no visible infiltrates, no apparent abnormalities, both sinuses phrenicocostal sharp. Conclusion: cardiomegaly. The patient was diagnosed with Diabetes Mellitus + Diabetic Nephropathy + severe metabolic acidosis + hyperkalemia + diabetic ulcers humerus dextra + Sepsis + hypoalbuminemia.

The patient underwent examinations of blood, urine, and pus, fasting blood and 2 hours postprandial blood glucose, $\mathrm{HbA1C}$, and lipid profile. The patient underwent hemodialysis cito and 4 liters of nasal oxygen therapy, diet B3 2,100 $\mathrm{kcal} /$ day, fluid balance input $=$ output $+500 \mathrm{ml}$, infusion of $\mathrm{NaCl} 0.9 \% 500 \mathrm{cc}$ in 24 hours, $2 \times 1$ gram of ceftriaxone injection, $3 \times 500 \mathrm{mg}$ of metronidazole injection, 6 subcutaneous units of injection of insulin aspart 3 times, $20 \mathrm{mg}$ of furosemide injection 2 times, $150 \mathrm{mg}$ of irbesartan 1 times, $1 \mathrm{mg}$ of folic acid 3 times and wound treatment for 2 days.

\section{DISCUSSION}

Diabetes mellitus is a clinical syndrome of metabolic abnormalities characterized by the presence of hyperglycemia caused by insulin secretion defects, insulin working defects or both (ADA., 2016). The underlying mechanism of metabolic disorders in type $2 \mathrm{DM}$ is known as "ominous octet" consisting of 1 . insulin resistance in muscle, 2. insulin resistance in the liver, 3 . decreased insulin secretion 
by pancreatic beta cells, 4 . increased free fatty acid in the blood, 5. decreased intracin hormone function in the intestine, 6. increased secretion of glucagon by pancreatic alpha cells, increased glucose reabsorption by the kidneys, and 8 . insulin resistance in the brain (Defronzo, 2009).

DMA criteria according to ADA include A1C $\geq$ $6.5 \%$, or fasting blood glucose $\geq 126 \mathrm{mg} / \mathrm{dl}$, or blood glucose after oral glucose tolerance test $\geq 200 \mathrm{mg} / \mathrm{dl}$, or the presence of classic hyperglycemia symptoms with random blood glucose $\geq 200 \mathrm{mg} / \mathrm{dl}$. Fasting blood glucose is blood glucose taken after no calorific intake for at least 8 hours. Random blood glucose is blood glucose value taken without regard to the last meal time. An oral glucose tolerance test was performed by administration of $75 \mathrm{mg}$ of anhydrous glucose in water (ADA., 2016).

The patient had a history of DM since 2005, taking glibenclamide but not regularly. The result of the fasting blood glucose test was $132 \mathrm{mg} / \mathrm{dL}$, prandial blood glucose $264 \mathrm{mg} / \mathrm{dL}$, and HbA1c $8.5 \%$ showed unregulated diabetes mellitus. $\mathrm{Hb} \mathrm{A} 1 \mathrm{c}$ examination in this patient was less accurate, considering the patient was found to be anemic which can affect HbAlc levels. Glycated Albumin examination can be an alternative to glycemic control index checks. TDHS is a specific complication of the hands experienced by DM patients in tropical countries (Okpara et al., 2015). TDHS became known by clinicians in developed countries around 1977 and around 1984 in developing countries. The first publication in the United States in 1984 by Mann Rj reported a hand ulcer accompanied by infection in patients with DM. The first publication in Africa in 1984 reported 3.2\% of DM sufferers in Nigeria suffering from TDHS. Libya reported the prevalence of TDHS of $3.1 \%$ of all diabetics and in Kenya $15 \%$ of all diabetic ulcers (Okpara et al., 2015). Prevalence of TDHS in China is $0.37 \%$ (Wang et al., 2010).

The anatomical location of TDHS is $57.7 \%$ in the fingers, $30.8 \%$ in the hand, and $11.5 \%$ in the arms. Clinical symptoms in TDHS such as inflammatory markers are generally swollen (tumor), pain (dolor), heat (heat), redness (rubor), and decreased function (functiolaesa) (Housihan et al., 2005). Risk factors for TDHS are being female, aged 50-60 years old, poor glycemic control, neuropathy, delay in seeking treatment, low socioeconomic conditions, living in coastal areas, and humid air conditions. This delay may occur due to limited access to health services or because the patient is not sensitive to the risk of life-threatening infections (Okpara et al., 2015; Papanas and
Maltezos, 2010; Al Matsubi et al., 2011).

Table 1: Tropical Hand Diabetic Syndrome Etiology (Houshian et al., 2006).

\begin{tabular}{|c|c|c|c|}
\hline & Etiology & Number & $\%$ \\
\hline Traum & & 146 & 34.9 \\
\hline \multicolumn{4}{|c|}{ Laceration/puncture: } \\
\hline- & Post-operative & 76 & 18.2 \\
\hline- & Foreign body & 71 & 17.0 \\
\hline- & Animal bites & 38 & 9.1 \\
\hline & Spontaneous & 28 & 6.7 \\
\hline & IV drug abuse & 14 & 3.3 \\
\hline- & Human bites & 8 & 1.9 \\
\hline & Secondary to other & 5 & 1.2 \\
\hline & focus & 28 & 6.7 \\
\hline- & Unknown & 4 & 1.0 \\
\hline \multicolumn{4}{|c|}{ - $\quad$ other } \\
\hline Total & & 418 & 100 \\
\hline
\end{tabular}

The patient had TDHS in the dextra humerus region. The etiology was the trauma of abrasions due to a fall when shopping in the market. Clinical symptoms were swelling, redness, pain, heat, and decreased function. Risk factors in these patients are being female, age over 52 years, poor glycemic control, and delay in seeking treatment.

The infection has an important role in the pathogenesis of TDHS. Approximately $85 \%$ of TDHS cases are initiated by infected wounds. In DM patients, thickening of the basement membrane inhibits leukocyte movement to the inflammatory area and precludes nutrient transfer. This explains the occurrence of necrosis and gangrene from minor trauma or infection in diabetic patients (Abbas and Archibald, 2005). Hand infection in DM patients generally starts from the site of skin trauma, which then spreads to subcutaneous tissue and soft tissue. Deeper infections may involve fascia, muscles, tendons, joints, and bones. The advent of gas in the subcutaneous layer can be triggered by Escherichia coli or other non-clostridial organisms (Okpara et al., 2015).

TDHS-induced bacteria are usually a combination of aerobic gram-negative bacteria with anaerobic enteral bacteria. Cultures of tissue are usually single bacteria, found in $>75 \%$ of cases (Okpara et al., 2015). Staphylococcus aureus is the most common bacteria found in isolation of TDHScausing bacteria, which is possible because it is a normal skin flora that can contaminate tissue wounds. In bacterial isolation, results can be positive for Enterobacter, Proteus, Escherichia coli, Klebsiella, or other anaerobic bacteria (Houshian et al., 2006; Papanas and Maltezos, 2010; Sabir et al., 2011). 
On examination of right-sided localis status, injury to the ventral region of the brachii dextra with pus and at the base of the wound there was full slough (+), with size $9 \times 3 \mathrm{~cm}$ and $2 \mathrm{~cm}$ depth into the muscle accompanied by inflammation marks of heat, dolor, rubor, and functio laesa. In this patient, gram-negative bacteria of Acinobacter Baumanni / Calcoacetius Complex were found on examination of pus cultures.

Interference with cell-mediated immunity (CMI), phagocyte function, and granulocytes resulting from diabetes mellitus increases the risk of hand infection (Sabir et al., 2011). When infection occurs, the area around the infection has edema, and small blood vessels become blocked and thrombosed. This occurs as a result of blocked flow due to the adhesion of leukocytes and platelets to the walls of blood vessels. The combination of these two factors leads to localized tissue ischemia and can develop into gangrene (Ezeani and Edo, 2014). Peripheral neuropathy may increase the risk of TDHS. The presence of neuropathy causes a decrease in sensory sensitivity to the extremities. This increases the tolerance of pain when exposed to trauma and makes the patient not pay attention to the wound. But in one study it was found that of 72 patients with TDHS, only $14 \%$ had peripheral neuropathy. Peripheral vascular disease only affected one patient (Abbas and Archibald, 2005).

In this patient the ankle-brachial index (ABI) value was 1.0. Sensory examination of the extremities using monofilament tests was not performed because the device was not available.

Diabetic nephropathy is the leading cause of kidney disease in patients receiving renal replacement therapy and occurs in $44 \%$ of all type 1 and 2 diabetes patients (Afshinnia and Brosius, 2015). Diabetic nephropathy is confirmed by a history of DM, presence of retinopathy, and proteinuria without other causes (Tjokroprawiro and Murtiwi, 2015). Diabetic nephropathy is divided into several eGFR-dependent stages. Below is a table of chronic kidney disease stages and clinical action plans.

In diabetic nephropathy dysfunction occurs in the vascular endothelial, smooth muscle cells of the blood vessels, as well as in the renal mesangial cells. This condition causes microvascular abnormalities of local ischemic locus and hypoxia. This causes a slowdown in wound healing. Terminal diabetic nephropathy conditions have a poor prognosis in TDHS patients (Ince et al., 2015). In contrast, sepsis complications in TDHS are risk factors for worsening renal function in diabetic nephropathy.
The patient was diagnosed with diabetic nephropathy based on the history of DM, fundoscopic examination of non-proliferative retinopathy, positive proteinuria 3 and Albumin Excretion Rate of $300 \mathrm{mg} / 24 \mathrm{~h}$.

Upon arrival at the hospital, the patient received blood urea nitrogen (BUN) $114 \mathrm{mg} / \mathrm{dl}$, serum creatinine $10.67 \mathrm{mg} / \mathrm{dl}$, and eGFR $7.44 \mathrm{ml} / \mathrm{min} / 1.73$ $\mathrm{m}^{2}$. At the time of polyclinic control, $20 \mathrm{mg} / \mathrm{dl} \mathrm{BUN}$ was found, with serum creatinine $2.01 \mathrm{mg} / \mathrm{dl}$, eGFR $29.3 \mathrm{ml} / \mathrm{min} / 1.73 \mathrm{~m}^{2}$. There was an improvement in glomerular filtration rate from stage $\mathrm{V}$ to stage IV due to the improvement of acute infection conditions. On wound observation during polyclinic therapy, the wound healed on the $35^{\text {th }}$ day after hospital treatment.

TDHS management includes hospitalization, elevation of ill hand, optimal blood glucose control, antibiotics and wound care in the form of incision, debridement, and drainage, if necessary, for further surgery and other rehabilitation measures. Optimal blood glucose control with insulin administration due to hyperglycemia worsens infection and slows wound healing, but otherwise, infections worsen the blood glucose metabolism (Papanas and Maltezos, 2010; Abbas and Archibald, 2005). In one study, the addition of hyperbaric oxygen therapy to standard therapy was a safe method to optimize the healing of TDHS (Aydin et al., 2014).

The patient was given $2 \times 1$ gram of ceftriaxone injection, $3 \times 500 \mathrm{mg}$ of metronidazole injection, $3 \times 6$ subcutaneous $3 \times 6$ insulin aspart, hand elevation, and wound treatment twice a week. The patient's wound gradually healed and the patient's blood glucose was controlled.

Kidney Disease Improving Global Outcomes (KDIGO) 2012 recommends patients with both DM and non-adult DM with PGK and urine albumin excretion $\geq 30 \mathrm{mg} / 24 \mathrm{~h}$ with TDS $>130 \mathrm{mmHg}$ or TDD $>80 \mathrm{mmHg}$, to be treated with antihypertensive drugs to maintain TDS $\leq 130$ $\mathrm{mmHg}$ or TDS $\leq 80 \mathrm{mmHg}$. It is recommended that angiotensin II receptor blocker (ARB) or angiotensin converting enzyme inhibitor (ACEi) is used in DM and non-adult DM patients with PGK and urine albumin excretion $>300 \mathrm{mg} / 24$ hours or equivalent (Eknoyan, 2013).

Insulin intensification therapy can prevent the onset and progression of microvascular DM including nephropathy in type 2 DM. Similarly, UKPDS finds that tight control of blood glucose with a target of $\mathrm{HbAlc}<7 \%$ can reduce overall microvascular complications (retinopathy and nephropathy) by $25 \%$ without taking into account 
how to achieve normoglycemia (UKPDS, 1998). The condition of sepsis in diabetic nephropathy patients may lead to deterioration of renal function characterized by impaired body fluid balance, electrolyte balance disorder, metabolic acidosis, heart failure, respiratory failure, and azotemia. Renal replacement therapy is needed when 1 . Anuria state, 2. Refractory hyperkalemia, 3.Asidemia $(\mathrm{pH}<7.0)$, 4. Uremic encephalopathy, 5. Neuropathy / uremic myopathy, 6. Pericarditis, 7. Sodium plasma abnormality $>155 \mathrm{mmol} / \mathrm{L}$ or $<120 \mathrm{mmol} / \mathrm{L}$ are found (Surachno and Bandaria, 2014).

For this patient, renal replacement therapy was performed in the form of hemodialysis cito for indication of severe metabolic acidosis and hyperkalemia. These patients are treated with fastacting analog insulin, namely $3 \times 6$ subcutaneous units of insulin aspart, $1 \times 150 \mathrm{mg}$ of irbesartan, and 1 x $20 \mathrm{mg}$ of Simvastatin. At the time of polyclinic control, blood pressure was $120 / 80 \mathrm{mmHg}$, fasting blood glucose was $120 \mathrm{mg} / \mathrm{dL}$, and blood glucose 2 hours post prandial was $166 \mathrm{mg} / \mathrm{dL}$. The target in these patients is TDS $\leq 130 \mathrm{mmHg}$, TDD $\leq 80$ $\mathrm{mmHg}$, and $\mathrm{HbA} 1 \mathrm{c}<7 \%$.

Terminal renal failure, peripheral neuropathy, and $\mathrm{HbA} 1 \mathrm{c}$ levels greater than $10 \%$ are significantly associated with poor prognosis in TDHS patients. Amputation is often necessary in patients with terminal renal failure who undergo routine hemodialysis with TDHS. This is due to the frequent occurrence of arterial calcification and arteriovenous shunt which causes circulatory disturbance and triggers gangrene in the upper extremities (Ince et al., 2015).

This patient had reached diabetic stage IV nephropathy and $\mathrm{HbA} 1 \mathrm{c} 8.5 \%$.

Education for TDHS patients and diabetic nephropathy is still the most important prevention tool in developing countries. Education is performed with a simple method by providing motivation and education on how to care for the hands and the importance of consultation with a doctor upon the early symptoms of TDHS, with lifestyle changes (stop smoking and light exercise 3-5 x week), lowfat diet, and adherence to taking drugs (Akhuemokhan et al., 2011; Afshinnia and Brosius, 2015).

\section{REFERENCES}

ABBAS, Z. G. \& ARCHIBALD, L. K. 2005. Tropical diabetic hand syndrome. Epidemiology, pathogenesis, and management. Am J Clin Dermatol, 6, 21-8.
ADA. 2016. Standars of Medical Care in Diabetes. In: CARE, D. (ed.) Supplement 1.

AFSHINNIA, F. \& BROSIUS, F. 2015. Approach to Chronic Kidney Disease in the Diabetic Patient., New York, Elsevier Inc.

AKHUEMOKHAN, K., ECHEKWUBE, P., BAKPA, F. \& KOKHERE, P. 2011. TDHS:Prevention Through Education. South Africa J, 24, 205-206.

AL MATSUBI, H., HAMDAN, F., ALHANBULI, O., ORIQUATE, G. \& MAHER, S. 2011. Dibetic hand syndrome as a clinical and diagnostic tool for diabetes melitus patient. Journal of Diabetes and Its Complication, 24, 154-162.

AYDIN, F., KAYA, A., SAVRAN, A., INCESU, M., KARAKUZU, C. \& OZTURK, A. M. 2014. Diabetic hand infections and hyperbaric oxygen therapy. Acta Orthop Traumatol Turc, 48, 649-54.

DEFRONZO, R. A. 2009. Banting Lecture. From the triumvirate to the ominous octet: a new paradigm for the treatment of type 2 diabetes mellitus. Diabetes, 58 , 773-95.

EKNOYAN, G. 2013. KDIGO 2012 Clinical Practice Guideline for the Evaluation and Management of Chronic Kidney Disease. Kidney International Supplement.

EZEANI, I. U. \& EDO, A. E. 2014. Case series on tropical diabetic hand syndrome. Niger J Clin Pract, 17, 5402.

HOUSHIAN, S., SEYEDIPOUR, S. \& WEDDERKOPP, N. 2006. Epidemiology of bacterial hand infections. Int J Infect Dis, 10, 315-9.

INCE, B., DADACI, M., ARSLAN, A., ALTUNTAS, Z., EVRENOS, M. K. \& FATIH KARSLI, M. 2015. Factors determining poor prognostic outcomes following diabetic hand infections. Pak J Med Sci, 31, 532-7.

OKPARA, T. C., EZEALA-ADIKAIBE, B. A., OMIRE, O., NWONYE, E. \& MALUZE, J. 2015. Tropical Diabetic Hand Syndrome. Ann Med Health Sci Res, 5, 473-5.

PAPANAS, N. \& MALTEZOS, E. 2010. The diabetic hand: a forgotten complication? $J$ Diabetes Complications, 24, 154-62.

SABIR, A. A., NJOKU, C. H. \& SADA, K. 2011. Tropical Diabetic Hand Syndrome in Tertiary Health Institution in Nigeria. Sahel Medical Journal, 144, 206-209

SURACHNO, R. G. \& BANDARIA, R. 2014. Gangguan Ginjal Akut. Dalam : Buku Ajar Ilmu Penyakit Dalam. Edisi Keenam, Jakarta, Interna Publishing.

TJOKROPRAWIRO, A. \& MURTIWI, S. 2015. Diabetes Melitus, Surabaya, Airlangga University Press.

UKPDS 1998. Intensive blood-glucose control with sulphonylureas or insulin compared with conventional treatment and risk of complications inpatients with type 2 diabetes. UK Prospective Diabetes Study.

WANG, C., LV, L., WEN, X., CHEN, D., CEN, S., HUANG, H., LI, X. \& RAN, X. 2010. A clinical analysis of diabetic patients with hand ulcer in a diabetic foot centre. Diabet Med, 27, 848-51. 